\title{
THE RESPONSE PROPERTY OF INVERTED SIPHON IN LONG DISTANCE WATER DISTRIBUTION SYSTEM
}

\author{
Mao Zhonghao, Guan Guanghua a , Yang Zhonghua and Zhong Ke \\ State Key Laboratory of Water Resources and Hydropower Engineering Science, Wuhan University, 430072 Wuhan, China
}

\begin{abstract}
In order to design controllers for canals with inverted siphon especially for very long siphon, it is necessary to learn its response property. Compared to open canals, the water movement in inverted siphon is very different due to the fast travelling speed of wave and high water pressure. It is impossible to use openchannel model describe invert siphon section, and the delay caused by the siphon haven't been discussed in existing literature. This paper proposes a response model of inverted siphon which contains a delay and an integrator in low frequencies, a constant gain in high frequencies. By comparing the response model to the results of simulation, this paper shows the response model is a good approximation. This paper studies a water distribution project consists of two canals and one inverted siphon. The result shows that the water level change at downstream end is significantly smaller than water change at upstream end. By applying response model of inverted siphon, this paper shows it is due to the delay of flow rate change from upstream end to downstream end.
\end{abstract}

\section{Introduction}

Open canals are usually used to deliver water in long distance water distribution systems because they are easy to construct and easy to repair, but they can't fill the needs to deliver water in cold regions or mountain areas. In some water distribution projects which are built in China, inverted siphons are widely used to deliver water cross mountains or rivers, some of the siphons are over $4 \mathrm{~km}$ long. In order to ensure the safety and efficiency of long distance and large scale inverted siphons, when water enter inverted siphons from open canals, the flow condition transferred to pressurized flow from freesurface flow.

Water in open canals is under free-surface flow condition where a disturbance happened at either end of a reach will take a long time to travel to either end[1]. An open canal can be divided into two parts: the uniform part corresponds to a pure delay and the backwater part corresponds to a pure integer[2]. The derivation of ID model helps engineers to design controller using linear control theory[3,4]. Litrico and Fromion[5] improve ID model by adding a zero to the ID model to account for the oscillations caused by flow changes, which is very helpful for the design of upstream water-level controllers[6].

Compared to open canals, water in inverted siphons is in pressurized flow condition where the travelling speed of wave can reach to $1000 \mathrm{~m} / \mathrm{s}$. Under such condition the change of water level at either end caused by the change of flow at either end is significant and the oscillations of water level is more intensive.
In the past few years, a lot of work is done on the simulation of transition between pressurized flow and free-surface flow, Lian Jijian et al.[7] used character line method to simulate the water transition between an open canal and an inverted siphon; Mu Xiangpeng et al.[8] compared the computation between character line method and implicit difference method and the results are fairly similar; Yang Kailin et al.[9] used shock capture method to simulate a long distance water distribution system with open canals and inverted siphons. But in order to apply modern control method to the control of water distribution systems with long distance inverted siphon, it is fundamental to learn the response property before designing the controllers.

\section{Response model}

Schuurmans proposed a canal pool response model called ID model which relates the water depth change at downstream end of a canal to the flow change at upstream and downstream end of the canal, the model contains a delay and an integer which corresponds to the uniform part and the backwater part of the canal, respectively. The ID model is rather accurate in modelling the water depth change at the downstream end and easy for controller designing. The ID model is

$$
\Delta h(k)=\frac{T_{s}}{A_{s}}\left[\Delta q_{u}\left(k-\tau_{R}\right)-\Delta q_{d}(k)\right]
$$

Where $\Delta \mathrm{h}(\mathrm{k})=$ change of water depth during time step $\mathrm{k}$; $\mathrm{k}=$ integer of time step; $\mathrm{T}_{\mathrm{s}}=$ duration of one time step; $\Delta \mathrm{q}_{\mathrm{u}}=$ change of flow rate at upstream end during time 
step $\mathrm{k} ; \Delta \mathrm{q}_{\mathrm{d}}=$ change of flow rate at downstream end during time step $\mathrm{k} ; \mathrm{A}_{\mathrm{s}}=$ surface of backwater area; $\tau_{R}=$ approximation of number of time step to delay time $\tau / \mathrm{T}_{\mathrm{s}}$. Delay time is the time dynamic waves requires to travel through the canal

$$
\tau=\frac{L}{C+V}
$$

Where $\mathrm{L}=$ distance along uniform part of the canal; $\mathrm{C}=\sqrt{ }(\mathrm{gA} / \mathrm{T})$ as the wave celerity with $\mathrm{g}$ as the gravitational velocity, $\mathrm{A}=$ wetted area, $\mathrm{T}=$ top width.

For canal under backwater, $A_{s}$ i top width $T$ multiples pool length $\mathrm{L}$

$$
\mathrm{A}_{s}=T L
$$

The top width can vary along the canal, one can get an reasonable approximation by dividing the backwater part into several parts and assumes the top width keep constant in each part.

Litrico and Fromion proved that ID model is an over simplification of canal response. For canals which are sufficiently short and completely affected by backwater, the dynamic waves don't dampen until it travels back and forth in a canal for several times, which causes the water depth changes in a high frequencies. The ID model ignores the gain of transfer function of water depth to flow rate in high frequency domain. They propose to add a constant gain to ID model to account for the water depth response at high frequency (IDZ model). The constant gain in the IDZ model represents the change of water depth when the dynamic waves arrive at the downstream end.

$$
\begin{aligned}
& \Delta h(k)=\frac{T_{s}}{A_{s}}\left[\Delta q_{u}\left(k-\tau_{R}\right)-\Delta q_{d}(k)\right] \\
& { }^{+} b_{u} \Delta q_{u}\left(k-\tau_{R}\right)-b_{d} \Delta q_{d}(k)
\end{aligned}
$$

Where $b_{u}, b_{d}$ positive constant of downstream water depth response to change of upstream flow rate and downstream flow rate.

\section{Shock capture method}

The shock capture method is based on a hypothetical slot at the top of an inverted siphon, shown as fig 1 . The slot width $B_{\mathrm{sl}}$ needs to be very small so that the difference of wetted area between realistic situation and hypothetical situation, and the speed of gravity wave needs to identical with pressure wave's propagation speed a. With this slot the movement of pressurized flow can be described using open canal equations[11,12,13].

$$
\begin{aligned}
& \frac{\partial y}{\partial t}+V \frac{\partial y}{\partial x}+\frac{A}{B_{s l}} \frac{\partial V}{\partial x}=0 \\
& g \frac{\partial y}{\partial x}+V \frac{\partial V}{\partial x}+\frac{\partial V}{\partial t}+g\left(S-S_{0}\right)=0
\end{aligned}
$$

Where $\mathrm{y}=$ water head, $\mathrm{V}=$ flow velocity, $\mathrm{A}=$ wetted area, $\mathrm{B}_{\mathrm{sl}}=\mathrm{gA} / \mathrm{a}^{2}$ as top width, $\mathrm{S}=\mathrm{n}^{2} \mathrm{v}^{2} / \mathrm{R}^{4 / 3}$ as hydraulic slope, $\mathrm{n}=$ relative roughness, $\mathrm{R}=$ hydraulic radius, $\mathrm{S}_{0}=$ bed slope.

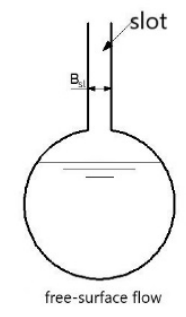

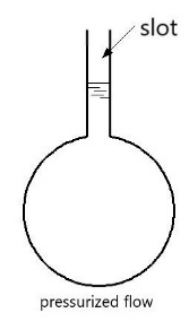

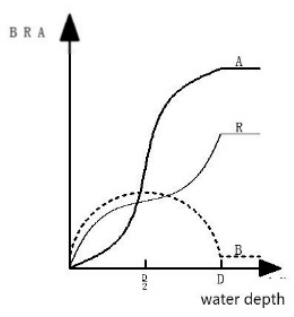

Figure 1. Hypothetical slot

In order to apply shock capture method to the simulation of pressurized flow, it is very important to get the correct velocity of wave. Peng Xinmin et al.[10] studied the influence of water head, pipe material and wall thickness on the velocity, in spite of air bub, the wave velocity can be computed according to equation 7 .

$$
\alpha=\frac{1}{\sqrt{\rho\left(\frac{1}{K}+\frac{d}{\delta+E}\right)}}
$$

Above, $\gamma=$ weight of water, $\mathrm{kg} / \mathrm{m}^{3}, \delta=$ thickness of wall, meters, $\mathrm{P}=$ water pressure, meters, $\mathrm{K}=$ elastic modulus, $\mathrm{Pa}$. In order to capture the movement of pressure wave in inverted siphon, the time step of simulation needs to be smaller than the time for a pressure wave to move from one end to the other end. Under such condition, the finite difference method would cause severe oscillation, this paper uses finite volume method to simulate the process[14,15].

\section{Response of inverted siphon}

An inverted siphon can be seen as an canal completely influenced by backwater, the wetted area and top width are constant along the canal, the top width is very small so the waves travel very fast, they travel in this canal for many times in a very short time causing the water depth changes in a high frequency.

Fig 2 shows the propagation of wave initiated by a flow rate change at the upstream end of an inverted siphon. With $\mathrm{Q}, \mathrm{A}, \rho$ the initial flow rate, wetted area, density; $\Delta \mathrm{Q}, \Delta \mathrm{A}, \Delta \rho$ as the change of flow rate, wetted area and density influenced by the waves; $c$ as the propagating speed of waves; $\mathrm{L}$ as the distance the waves go through during time $\tau ; \mathrm{H}_{2}$ as the water head at upstream end, $\mathrm{H}_{1}$ as the water head under initial state. 


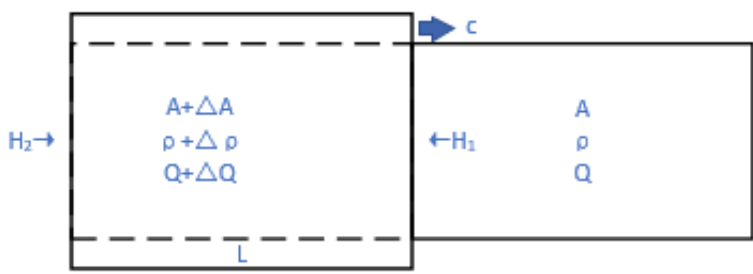

Figure 2. Flow rate change at the upstream end of an inverted siphon

For an short distance of $\mathrm{L}$, it is an reasonable simplification to think the wetted area, flow rate and density keep constant along the distance, according to the momentum conservation law and ignore the friction of wall

$[(\rho+\Delta \rho)(Q+\Delta Q)-\rho Q] L=$

$\rho g \tau\left[H_{1}(A+\Delta A)-H_{2}(A+\Delta A)\right]$

$L=\mathrm{c} \tau$

Normally the changes of density and wetted area are very small, ignore the terms contains $\Delta \mathrm{A}, \Delta \rho$

$H_{2}-H_{1}=\frac{\mathrm{c}}{\mathrm{Ag}} \Delta Q$

When the upstream flow rate changes, it causes the water head at upstream end rise by $\mathrm{c} \Delta \mathrm{Q} / \mathrm{Ag}$, when the waves reach the downstream end after a delay time of $\tau=\mathrm{L} / \mathrm{c}$ the downstream water head rise by $\mathrm{c} \Delta \mathrm{Q} / \mathrm{Ag}$, similar to the gain of water head to flow rate change in high frequency domain. The gain in low frequency domain is determined by surface of backwater area, is easy to get for an inverted siphon modelling by shock capture method, which is slot width $\mathrm{B}_{\mathrm{sl}}$, multiples length L.

Applying IDZ model to inverted siphon, we can get

$$
\begin{aligned}
& \Delta h_{d}(k)=\frac{T_{s}}{A_{s}}\left[\Delta q_{u}\left(k-\tau_{R}\right)-\Delta_{q_{d}}(k)\right] \\
& { }^{+} b_{u} \Delta q_{u}\left(k-\tau_{R}\right)-b_{d} \Delta q_{d}(k)+\Delta h_{u}\left(k-\tau_{R}\right)
\end{aligned}
$$$$
\Delta h_{u}(k)=b_{u} \Delta q_{u}(k)
$$

$$
A_{s}=L B_{s l}
$$

$$
\tau_{R}=\frac{L}{a T_{s}}
$$

$$
b_{u}=\frac{c}{A g}
$$

$$
b_{d}=\frac{c}{A g}
$$

\section{Model and simulation}

This paper selects an inverted siphon of Dian Zhong water distribution for simulation, the inverted siphon is consisted of five identical round pipes placed next to each other. Parameters of this model are listed in table 1.

Table 1. Parameters of inverted siphon

\begin{tabular}{|c|c|}
\hline Length(m): & 516 \\
\hline Radius(m): & 4 \\
\hline Pore number: & 5 \\
\hline Bed slope: & $1 /-490$ \\
\hline Relative roughness: & 0.014 \\
\hline
\end{tabular}

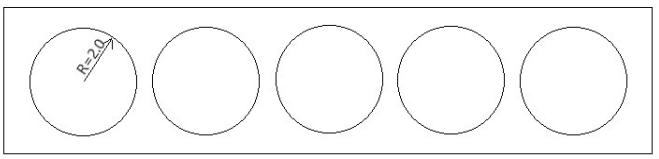

Figure 3. Cross-section of inverted siphon

In Dian Zhong water distribution project, the intake structure is a pump station contains 18 pumps, each pump has a designed water transport capacity of $7.5 \mathrm{~m}^{3} / \mathrm{s}$. In test 1 , consider the situation where 16 pumps are open at the initial state and then one more pump is open resulting the inlet flow of inverted siphon rises by $7.5 \mathrm{~m}^{3} / \mathrm{s}$ after simulation starts for 6 seconds, the flow rate at downstream end keeps constant, in test two, consider the situation where 14 pumps are open at the initial state then two more pumps are open resulting the inlet flow of inverted siphon rises by $15 \mathrm{~m}^{3} / \mathrm{s}$ after simulation starts for 6 seconds, the flow rate at downstream end keeps constant. In both tests, the velocity of pressure wave in inverted siphon is $1000 \mathrm{~m} / \mathrm{s}$ according to equation 5 , the slot width $\mathrm{Bs}=6.15^{*} 10^{-4} \mathrm{~m}$, the distance between each cross-section is $5.10 \mathrm{~m}$, because the Courant number needs to be smaller than 1 , the time step is chosen to be $0.005 \mathrm{~s}$.

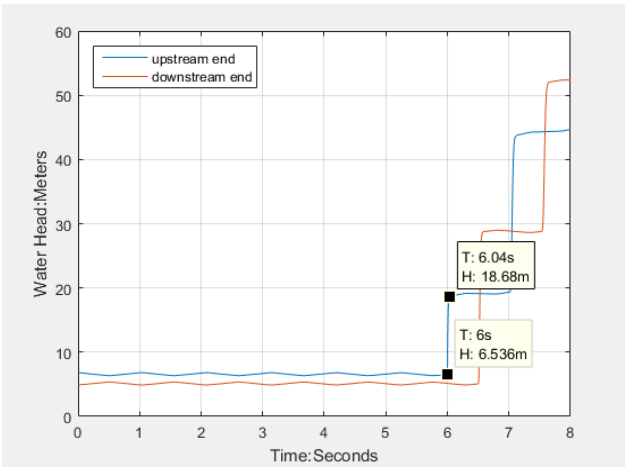




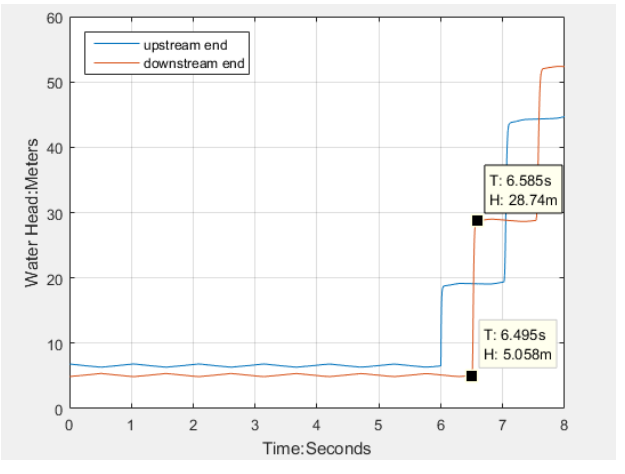

Figure 4. Change of water head at upstream end and downstream end for test 1
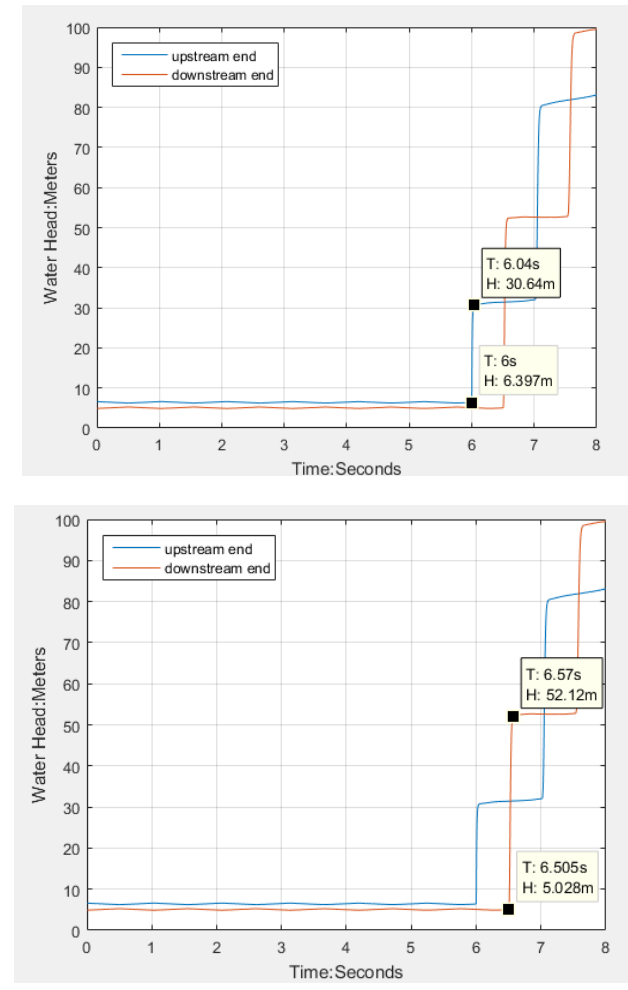

Fig 5. Change of water head at upstream end and downstream end for test 2

Parameters of response model of inverted siphon are

\begin{tabular}{ccccc}
\hline $\mathrm{T}_{\mathrm{s}}$ & $\mathrm{A}_{\mathrm{s}}$ & $\tau_{\mathrm{R}}$ & $\mathrm{b}_{\mathrm{u}}$ & $\mathrm{b}_{\mathrm{d}}$ \\
\hline 0.005 & 0.317 & 103 & 1.624 & 1.624 \\
\hline
\end{tabular}

The response model is

$\Delta h_{u}(k)=1.624 \Delta q_{u}(k)$

$$
\begin{aligned}
& \Delta h_{d}(k)=\frac{0.005}{0.317}\left[\Delta q_{u}(k-103)-\Delta q_{d}(k)\right] \\
& +1.624 \Delta q_{u}(k-103)-1.624 \Delta q_{d}(k) \\
& +\Delta h_{u}(k-103)
\end{aligned}
$$

The results of water change at upstream end and downstream end obtained using response model fit finite volume method very well.

\section{Influence on water fluctuation}

In water distribution project, inverted siphons and canal pools are connected to each other. To study the influence of inverted siphon in project, it is necessary to build a model contains an inverted siphon and open canals.

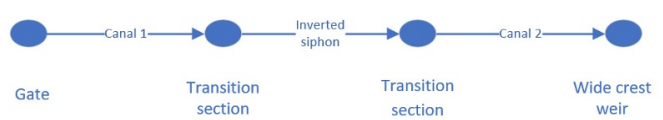

Figure 6. Model of water distribution project

This model contains two canals and one inverted siphon, canal 1 and canal 2 are prismatic canals with trapezoidal cross-section, the inverted siphon is a round pipe. A gate is placed at the upstream end of canal 1 to control the flow rate, canal 1, canal 2 and inverted siphon are connected by a transition section. A wide crest weir is placed at the downstream end of canal 2. There is no outlet in this model, some parameters are

Table 2. Parameters of open canal and inverted siphon

\begin{tabular}{lllllll}
\hline & $\mathrm{L}$ & $\mathrm{S}$ & $\mathrm{n}$ & $\mathrm{m}$ & $\mathrm{b}$ & $\mathrm{R}$ \\
\hline open canal 1 & 1000 & $5 / 10000$ & 0.015 & $1: 2$ & 2 & \\
\hline open canal 2 & 1000 & $5 / 10000$ & 0.015 & $1: 2$ & 2 & \\
\hline inverted siphon & 2000 & 0 & 0.014 & $1: 2$ & & 2 \\
\hline
\end{tabular}

Where $\mathrm{L}=$ length; $\mathrm{S}=$ bed slope; $\mathrm{n}=$ relative roughness; $\mathrm{m}=$ side slope; $\mathrm{b}=$ bed width; $\mathrm{R}=$ diameter. The initial flow rate is $3 \mathrm{~m} 3 / \mathrm{s}$, after $5 \mathrm{~min}$, the flow rate rises to $8 \mathrm{~m} 3 / \mathrm{s}$ and keeps constant until the end, by comparing the changes of water depth at upstream end of inverted siphon and downstream end of inverted siphon, it is obvious that the water depth changes at downstream end of inverted siphon are smaller than at upstream end.

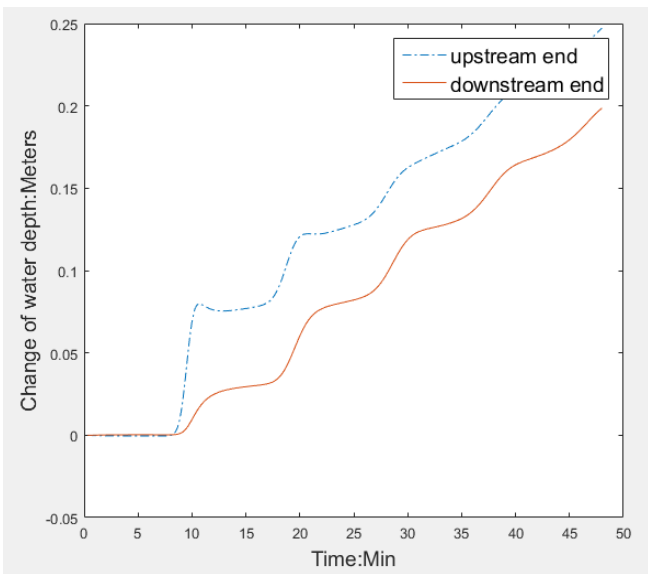

Figure 7. Water depth change 


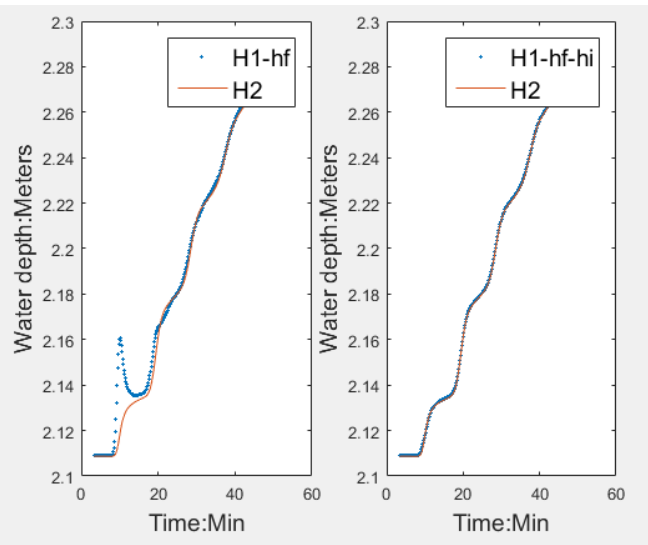

Figure 10. Comparison of $\mathrm{H}_{\mathrm{u}}-\mathrm{h}_{\mathrm{f}}$ and $\mathrm{H}_{\mathrm{d}}, \mathrm{H}_{\mathrm{u}}-\mathrm{h}_{\mathrm{f}}-\mathrm{h}_{\mathrm{i}}$ and $\mathrm{H}_{\mathrm{d}}$

For an inverted siphon, according to the response model, we can get

$$
\begin{aligned}
& \Delta h_{d}(k)=\frac{T_{s}}{A_{s}}\left[\Delta_{q_{u}}\left(k-\tau_{R}\right)-\Delta_{q_{d}}(k)\right] \\
& { }^{+} b_{u} \Delta q_{u}\left(k-\tau_{R}\right)-b_{d} \Delta q_{d}(k)+\Delta h_{u}\left(k-\tau_{R}\right)
\end{aligned}
$$

$\Delta h_{u}(k)=b_{u} \Delta q_{u}(k)$

Because there is no outlet in inverted siphon, the response of downstream flow rate to upstream flow rate change is a pure delay with delay time $\tau=\mathrm{L} / \mathrm{a}$

$$
\Delta q_{d}(k)=\Delta q_{u}\left(k-\tau_{R}\right)
$$

Adding equation 21 to equation 19 and 20:

$$
\Delta h_{d}(k)-\Delta h_{u}(k)=\frac{c}{A g}\left[\Delta q_{u}\left(k-\tau_{R}\right)-\Delta q_{u}(k)\right]
$$

The water depth at upstream end and downstream end of inverted siphon under initial state $\mathrm{H}_{\mathrm{u} 0}$ and $\mathrm{H}_{\mathrm{d} 0}$ follows

$H_{u 0}-H_{d 0}=\left(S_{f}-S_{0}\right) L$

After a period of time $\tau$, The water depth at upstream end and downstream end of inverted siphon $\mathrm{H}_{\mathrm{u} \tau}$ and $\mathrm{H}_{\mathrm{d} \tau}$ follows

$$
\begin{aligned}
& H_{u \tau}-H_{d \tau}=\sum_{k=0}^{\tau_{R}} \Delta h_{u}(k)-\sum_{k=0}^{\tau_{R}} \Delta h_{d}(k)+\left(\overline{S_{f}}-S_{0}\right) L \\
& \sum_{k=0}^{\tau_{R}} \Delta h_{u}(k)-\sum_{k=0}^{\tau_{R}} \Delta h_{d}(k)=\frac{c}{A g}\left[q_{u}\left(\tau_{R}\right)-q_{u}(0)\right]
\end{aligned}
$$

Where $\overline{S_{f}}=$ average hydraulic slope during time $\tau$, applying Taylor series of $\mathrm{q}_{\mathrm{u}}$

$H_{u}(t)-H_{d}(t)=\frac{L}{A g} \frac{d q_{u}(t)}{d t}+\left(\overline{S_{f}}-S_{0}\right) L$
The difference of changes of water depth at upstream end and downstream end is due to the hydraulic slope and the delay time, let $\mathrm{h}_{\mathrm{f}}=\left(\overline{S_{f}}-S_{0}\right) L, \mathrm{~h}_{\mathrm{i}}=\frac{L}{A g} \frac{d q_{u}(t)}{d t}$, by comparing $\mathrm{H}_{\mathrm{u}}-\mathrm{h}_{\mathrm{f}}$ and $\mathrm{H}_{\mathrm{d}}, \mathrm{H}_{\mathrm{u}}-\mathrm{h}_{\mathrm{f}}-\mathrm{h}_{\mathrm{i}}$ and $\mathrm{H}_{\mathrm{d}}$, it is obvious that $\mathrm{H}_{\mathrm{u}}-\mathrm{h}_{\mathrm{f}}-\mathrm{h}_{\mathrm{i}}$ is a good match of $\mathrm{H}_{\mathrm{d}}$, see Fig 9 and Fig 10.

\section{Conclusions}

In this paper, the authors use shock capture method and finite volume method to simulate the water depth changes at upstream end and downstream end caused by a step flow rate change at upstream end of an inverted siphon. Studying the behavior in low frequencies and high frequencies, the authors come up with the response model of inverted siphons. By comparing the results of response model and finite volume method, the authors prove that this model is a good approximation.

The authors also build a model of water distribution project contains open canals and an inverted siphon, the results of simulation shows that for a flow rate change at upstream end of an inverted siphon, the water depth changes at upstream end are significantly larger than the water depth changes at downstream end, by applying the response model, the authors get the expression of difference of water depth changes at two ends. The following conclusions can be drawn:

1.The pressure waves in inverted siphon are very fast, in order to capture the propagation process of waves, the time step of simulation needs to be very small, also, due to the severe changes of pressure in inverted siphons, finite difference method is not appropriate for simulation, while finite volume method can alleviate computation oscillation without causing too much deviation.

2. Inverted siphon's response model needs to account for behavior in both low frequencies and high frequencies. In low frequencies, the behavior is dominated by the integrator and the delays, for high frequencies, the delay and waves are predominant, for simplicity, the waves can be approximated by a constant gain, the value of constant gain is similar to water head change caused by water hammer.

3. According to the response model of inverted siphon, it is due to the delay of flow rate change at downstream end to the upstream end. The difference of water depth change in upstream end and downstream end can be described using hydraulic slope plus the derivative of flow rate change multiples a constant., the longer the inverted siphon is or the faster the flow rate changes at upstream, the bigger the difference is.

4. Compared with open canals, the water depth changes at downstream caused by flow rate change at upstream end is much larger, with the longer inverted siphon, the faster upstream flow rate changes, the larger downstream water depth changes will be. While scheduling the water delivery plan, the changes of water depth in inverted siphons cannot be neglected.

The results show that an inverted siphon helps to damp the oscillation of water depth, the damping effect is in direct proportion to the length of inverted siphon and the derivative of flow rate. One needs to consider the 
head-loss and damping effect while approximating inverted siphon with a node in canals.

One inadequacy of this paper is that it doesn't consider the variation of wave speed in inverted siphons. The speed of wave is related to the pressure, in long distance inverted siphons, the pressure at different crosssections may have big difference, in short distance inverted siphons which are less than 1000 meters, the difference in wave speed can be negligible.

\section{Acknowledgment}

Project supported by National Key R\&D Program of China (Grant No. 2016YFC0401810) and National Natural Science Foundation of China (No. 51439006, 51679170)

\section{References}

1. G. Belaud, X. Litrico, A. J. Clemmens, "Response Time of a Canal Pool for Scheduled Water Delivery." Journal of Irrigation and Drainage Engineering 139, 4: 300-308 (2013)

2. J. Schuurmans, A. J. Clemmens, S. Dijkstra, A. Hof, R. Brouwer, "Modelling of Irrigation and Drainage Canals for Controller Design" Journal of Irrigation and Drainage Engineering 125, 6: 338-344 (1999)

3. X. Litrico, P. O. Malaterre, J. P. Baume, P. Y. Vion, J. Ribot Bruno, "Automatic Tuning of PI Controllers for an Irrigation Canal Pool" Journal of Irrigation and Drainage Engineering 133, 1: 27-37 (2007)

4. A. J. Clemmens, R. J. Strand, "Downstream-WaterLevel Control Test Results on the WM Lateral Canal." Journal of Irrigation and Drainage Engineering 136, 7: 460-469 (2010).

5. X. Litrico, V. Fromion, "Simplified Modelling of Irrigation Canals for Controller Design" Journal of Irrigation and Drainage Engineering 130, 5: 373-383 (2004)

6. A. J. Clemmens, X. Tian, P. J. Overloop, X. Litrico, "Integrator Delay Zero Model for Design of Upstream Water-Level Controllers", Journal Of Irrigation And Drainage Engineering 143, 3: (2017)

7. Lian Jijian, Wang Jun, Wan Wuyi, Wang Yuncang, "Calculations of Hydraulic Transient for Complex Water Supply Systems by Using Characteristic Method with Variable Time Steps", Water Resources and Hydropower Engineering 34, 9:12-14 (2003)

8. $\mathrm{Mu}$ Xiangpeng, Lian Jijian, Liu Hanhe, "Comparison and Applicability Analysis of Numerical Methods for Transient of Complex Water Diversion System", Journal of Tianjin University 41, 5: 515-521 (2008)

9. Yang Kailin, Wu Huanying, Jiang Yunnu, "Numerical Simulation of Hydraulic Transients in Conduit Networks for Water Transfer with Retaining Weirs", Journal of Hydraulic Engineering 38, 3: 306-311 (2007)
10. Peng Xinmin, $\mathrm{Mu}$ Xiangpeng, Wan Wuyi, "Influence of Head Pressure and Pipe Characteristic on the Change of Water Hammer Wave Speed", Water Resources and Hydropower Engineering 35, 11:84-86 (2004)

11. M. Fuamba, "Contribution on transient flow modelling in storm sewers", Journal of Hydraulic Research 40, 6: 685-693 (2015)

12. A. Malekpour, B. W. Karney, "A Non-oscillatory Preissmann Slot Method Based Numerical Model", Procedia Engineering, 89: 1366-1373 (2014)

13. A. Maranzoni, S. Dazzi, F. Aureli, P. Mignosa, "Extension and application of the Preissmann slot model to 2D transient mixed flows", Advances in Water Resources 82: 70-82 (2015)

14. A. S. León, M. S. Ghidaoui, A. R. Schmidt, M. H. García, "Application of Godunov-type schemes to transient mixed flows". Journal of Hydraulic Research 48, 5: 686-688 (2010)

15. EF. Toro, Shock Capturing Methods for FreeSurface Shallow Flows, John Wiley, 2001: 566-571. 